\title{
Parasympathetic dysfunction in rheumatoid arthritis patients with ocular dryness
}

\author{
P J Barendregt, G L van der Heijde, F C Breedveld, H M Markusse
}

\begin{abstract}
Objective-To determine whether abnormalities in the function of the autonomic nervous system are associated with oral and ocular dryness in rheumatoid arthritis.

Methods-Pupillography was done using an infrared light reflection method (IRIS) to measure both parasympathetic function (constriction latency and the latency of maximum constriction velocity (MCV)) and sympathetic function (dilatation latency) in rheumatoid arthritis patients with and without ocular dryness. The Schirmer and Saxon tests were used to measure the tear and saliva production respectively.

Results-The Schirmer and Saxon test results in rheumatoid arthritis patients with ocular dryness were reduced $(P<$ 0.05) compared with rheumatoid arthritis patients without ocular dryness and healthy controls. Constriction latency and MCV latency were prolonged in rheumatoid arthritis patients with ocular dryness compared to the other two groups ( $P<$ 0.05). A negative correlation was found between the degree of ocular dryness and both constriction latency and MCV latency. No correlation was found between the results of pupillography and saliva production.
\end{abstract}

Conclusions-Parasympathetic dysfunction may play a role in ocular dryness in patients with rheumatoid arthritis.

Department of Rheumatology, Dr Daniel Den Hoed Clinic, Rotterdam, The Netherlands P J Barendregt H M Markusse

Department of Medical Physics and Medical Informatics, Free University Hospital, Amsterdam, The Netherlands

Department of Rheumatology, University Hospital Leiden, Leiden, The Netherlands

F C Breedveld

Correspondence to: P J Barendregt, Department of Rheumatology, Dr Daniel Den Hoed Clinic, PO Box 5201, 3008 AE Rotterdam, The Netherlands.

Accepted for publication 23 April 1996
The pupillary light reflex, which is exclusively regulated by the autonomic nervous system, can easily be measured by using a recently developed infrared light reflec-
Table 1 Distribution of Schirmer test values in patients with rheumatoid arthritis

\begin{tabular}{lllll}
\hline \multicolumn{2}{l}{ With ocular dryness $(n=18)$} & & \multicolumn{2}{l}{ Without ocular dryness $(n=18)$} \\
\cline { 1 - 1 } Test result & $n$ & & Test result & $n$ \\
\hline $0.00-2.49$ & 10 & & $10.00-18.99$ & 4 \\
$2.50-5.00$ & 3 & & $19.00-27.99$ & 6 \\
$5.01-9.99$ & 5 & & $28.00->35.00$ & 8 \\
\hline
\end{tabular}

Schirmer values in $\mathrm{mm} / 5 \mathrm{~min}$.

tion method (IRIS). ${ }^{12}$ The aim of this study was to investigate whether oral and ocular dryness in rheumatoid arthritis patients can be attributed to autonomic dysfunction as determined by the IRIS method for pupillography.

\section{Methods}

PATIENTS

Three groups of age matched women were studied:

Group $1-18$ women with rheumatoid arthritis according to the ARA criteria ${ }^{13}$ aged 32 to 82 years (mean 62 years) with a disease duration of 3 to 54 years (mean 22 years) selected from the department of rheumatology, Dr Daniel den Hoed Clinic, Rotterdam. All patients had complaints of dryness of the eyes or the mouth and the results of a Schirmer's test $^{14}$ were $<10 \mathrm{~mm} / 5 \mathrm{~min}$ (table 1 ).

Group 2- 18 women with rheumatoid arthritis aged 24 to 75 years (mean 55 years) with a disease duration of 2 to 28 years (mean 10 years) selected from the same department. These patients had no complaints of dryness of the eyes or mouth and the results of a Schirmer's test ${ }^{14}$ were $\geq 10 \mathrm{~mm} / 5 \mathrm{~min}$ (table 1 ).

The women of groups 1 and 2 were consecutive rheumatoid arthritis patients who were recruited to the study after considering the exclusion criteria, and then divided in the two subgroups according to the sicca symptoms and Schirmer's test.

Group $3-33$ women aged 26 to 82 (mean 57 years), who were relatives of patients or hospital employees, served as healthy controls.

None of the women studied suffered from neurological disease, amyloidosis, renal failure, diabetes mellitus, or other diseases known to interfere with the autonomic nervous system. Women with drug treatment interfering with the autonomic nervous system, including diuretics, antiarrhythmics, neuroleptics, and antiepileptic and antidepressive drugs, were excluded from the study. Patients with a history of ophthalmopathy, as well as those using eye drops interfering with the autonomic nervous system, were also excluded. 
CLINICAL INVESTIGATION

The disease activity of the rheumatoid arthritis patients was determined by means of the disease activity score (DAS) (range from 0 to 8), which incorporates the Ritchie articular index, the number of swollen joints, and the erythrocyte sedimentation rate (ESR). ${ }^{15}$ A neurological examination included peripheral reflexes and distal sensation in the legs.

MEASUREMENT OF TEAR PRODUCTION (SCHIRMER TEST)

Standardised paper strips (IOLAB Pharmaceuticals) were placed in the lower eyelids of the unanaesthetised eyes. The wetting of the strips in millimetres after five minutes was averaged for both eyes.

\section{MEASUREMENT OF SALIVA PRODUCTION (SAXON} TEST)

To perform the Saxon test, ${ }^{16}$ a piece of parafilm $(5 \times 5 \mathrm{~cm})$ and a plastic tube were weighed and the individual was asked to chew vigorously on parafilm for two minutes. The chewed parafilm and all the saliva produced were placed together in tube supplied. The amount of saliva produced was obtained by subtracting the original weight from the weight of the tube after chewing. Weights were measured on a Mettler laboratory balance which is accurate to $0.1 \mathrm{mg}$.

\section{PUPILLOGRAPHY}

The pupillary light reactions were measured with the IRIS method as previously described. ${ }^{12}$ In short, after one minute dark adaption infrared light was emitted from diodes located on a frame in front of the eye. On the same frame phototransmitters detected the infrared light reflected from the iris while the infrared light entering the pupil was absorbed. The pupillary system was stimulated by a stepwise change of the luminance of an infrared light source of fixed intensity. Each eye was measured during six light responses with a sample frequency of $100 \mathrm{~Hz}$. The latency times of these six responses were averaged. Average constriction latency (the time between the start of the light pulse and the start of the constriction of the pupil) and the latency of the maximum constriction velocity (MCV; the time between the start of the light pulse and maximum constriction velocity) were determined as indices of parasympathetic function. ${ }^{12}$ The average dilatation latency (the time between the disappearance of the light pulse and the start of the dilatation of the pupil) was determined as an index of sympathetic function. ${ }^{10}$

STATISTICS

The Mann-Whitney $U$ test and the $\chi^{2}$ test were used where appropriate. All correlations were analysed by means of Kendall's rank correlation test.

\section{Results}

Clinical and demographic data of the rheumatoid arthritis patients and controls are presented in table 2 .
Table 2 Clinical and demographic data of 36 patients With rheumatoid arthritis (RA) and 33 controls. Data are median (range) unless otherwise indicated.

\begin{tabular}{|c|c|c|c|}
\hline & $\begin{array}{l}R A \text { patients } \\
\text { with ocular } \\
\text { dryness }\end{array}$ & $\begin{array}{l}\text { RA patients } \\
\text { without ocular } \\
\text { dryness }\end{array}$ & Controls \\
\hline $\begin{array}{c}\text { Number of } \\
\text { patients }\end{array}$ & 18 & 18 & 33 \\
\hline Age (years) & $64(32-82)$ & $59(24-75)$ & $56(26-82)$ \\
\hline $\begin{array}{l}\text { Disease } \\
\text { duration } \\
\text { (years) }\end{array}$ & $21(3-54)^{\star}$ & $7(2-28)$ & \\
\hline $\begin{array}{l}\text { Serology (\% } \\
\text { positive) }\end{array}$ & $94^{\star}$ & 56 & \\
\hline $\begin{array}{c}\text { Erosions (\% } \\
\text { positive) }\end{array}$ & 100 & 83 & \\
\hline Ritchie index & $12(0-32)$ & $4(0-53)$ & \\
\hline $\begin{array}{l}\text { Swollen joints } \\
\text { (n) }\end{array}$ & $3(0-8)$ & $3(0-18)$ & \\
\hline $\operatorname{ESR}(\mathrm{mm} / \mathrm{h})$ & $44(4-110)$ & $34(9-109)$ & \\
\hline DAS score & $3.3(1.6-5.0)$ & $2.6(1-6.2)$ & \\
\hline $\begin{array}{l}\text { Schirmer (mm/5 } \\
\text { min) }\end{array}$ & $2(0-9) \ddagger$ & $26(13-35)$ & $17(4-35)$ \\
\hline $\begin{array}{l}\text { Saxon (mg/2 } \\
\text { min) }\end{array}$ & $\begin{array}{l}0.6 \\
(0.2-2.4)^{\star} t\end{array}$ & $1.1(0.3-3.7)$ & $1.3(0.2-4.8)$ \\
\hline
\end{tabular}

ESR, erythrocyte sedimentation rate; DAS, disease activity score;

${ }^{\star} \mathrm{P}<0.05 v \mathrm{RA}$ without dryness.

$\star \mathrm{P}<0.05 v \mathrm{RA}$ with
$+\mathrm{P}<0.01 v$ control.

$\ddagger \mathrm{P}<0.001 v \mathrm{RA}$ without dryness and control.

Table 3 Pupil constriction and pupil dilatation latency times in 36 patients with rheumatoid arthritis $(R A)$ and 33 controls. Values are median (range).

\begin{tabular}{llll}
\hline & $\begin{array}{l}\text { RA patients } \\
\text { with ocular } \\
\text { dryness }\end{array}$ & $\begin{array}{l}\text { RA patients } \\
\text { without ocular } \\
\text { dryness }\end{array}$ & Controls \\
\hline CL & 260 & 245 & 250 \\
MCV & $(240-300)^{\star}$ & $(220-290)$ & $(180-300)$ \\
& 350 & 320 & 325 \\
DL & $(250-370)+5$ & $(270-390)$ & $(270-370)$ \\
& 390 & 390 & 350 \\
& $(180-510)$ & $(250-510)$ & $(200-500)$ \\
\hline
\end{tabular}

$\mathrm{CL}$, constriction latency time (ms); $\mathrm{MCV}$, latency time of the maximum constriction velocity (ms); DL, dilatation latency time (ms)

* $\mathrm{P}<0.05 v \mathrm{RA}$ without dryness and controls.

$\widehat{P}=0.05 v \mathrm{RA}$ without dryness.

$+\mathrm{P}<0.01 v$ controls.

\section{TEAR AND SALIVA PRODUCTION}

The results of the Schirmer and Saxon tests are also shown in table 2. The patients with ocular dryness produced significantly less tears and saliva than the patients without ocular complaints and the controls.

\section{PUPIILOGRAPHY}

In the group of rheumatoid arthritis patients with ocular dryness the constriction latency time and the MCV latency were longer than in both the patient group without ocular dryness and the controls (table 3). Only the difference between MCV latency time in the rheumatoid arthritis patients with ocular dryness and those without ocular dryness was of borderline statistical significance $(P=0.05)$.

Dilatation latency time did not differ between the groups investigated.

We also divided the rheumatoid arthritis patients with ocular dryness in two subgroups according to the results of the Schirmer test (group 1a: Schirmer test $\leq 5 \mathrm{~mm} / 5 \mathrm{~min}$, group 1b: Schirmer test $>5 \mathrm{~mm} / 5 \mathrm{~min}$ and $<10$ $\mathrm{mm} / 5 \mathrm{~min})$. No statistically significant differences in constriction latency, dilatation 
latency, and MCV latency were found between these two groups.

In the rheumatoid arthritis patients a negative correlation was found between the results of the Schirmer test and both constriction latency $(\rho 0.321, P<0.05)$ and the MCV latency ( $\rho 0.327, P<0.05)$. No correlation was found between the results of the Schirmer test and dilatation latency time.

In the rheumatoid arthritis patients no correlation was found between the results of the Saxon test and the results of pupillography.

Considering all rheumatoid arthritis patients, no correlation was found between the results of pupillography and DAS score, age, or disease duration.

\section{PERIPHERAL NERVOUS SYSTEM}

Peripheral polyneuropathy, defined as the absence of the Achilles tendon reflex and absent vibration sensation in the distal legs (first metatarsophalangeal joint, lateral malleolus) was found in 13 out of $31(42 \%)$ of the rheumatoid arthritis patients tested.

In the patients with clinical signs of peripheral polyneuropathy, four out of 13 patients $(31 \%)$ had prolonged constriction latency and MCV latency ( $>$ 1SD above the controls), as compared to six out of 18 patients $(30 \%)$ without signs of peripheral polyneuropathy.

\section{Discussion}

This study showed that there is parasympathetic dysfunction in rheumatoid arthritis patients with ocular dryness, established by a prolonged constriction latency time and a MCV latency, and a negative correlation between these latencies and tear production. Evidence for sympathetic dysfunction was not found in these patients. The constriction latency and MCV latency times did not correlate with saliva production.

The IRIS method was used because it is easy to perform and is not associated with side effects. In diabetes mellitus a good correlation has been found between this method and those of the more conventional methods for detecting autonomic neuropathy, including cardiovascular reflex tests. ${ }^{12}$

In patients with inflammatory joint diseases, parasympathetic dysfunction has previously been found by means of pupillography ${ }^{17}$ and cardiovascular function tests. In the study described by Perry et al ${ }^{17}$ the rate of pupil constriction in response to a light flash was decreased in rheumatoid arthritis patients. A raised baseline heart rate and a diminished bradycardic response on the release of the Valsalva manoeuvre were also found in this patient group.

Several studies on rheumatoid arthritis patients have also detected abnormal heart rate responses on parasympathetic function tests. $^{6718}$ In a study by Leden et $a l^{6}$ an increased heart rate at rest and an abnormal heart rate reflex to tilting was found in patients with severe rheumatoid arthritis. Similar findings were described by Edmonds et al, ${ }^{18}$ who found an abnormal heart rate response to standing up in $33 \%$ of rheumatoid arthritis patients. More than half of these patients also had clinical evidence of peripheral neuropathy. Finally, a study by Toussirot et $a l^{7}$ showed autonomic dysfunction in half of a group of 50 rheumatoid arthritis patients.

Peripheral neuropathy is thought to be due to vasculitis in rheumatoid arthritis and the possibility that autonomic neuropathy may develop through the same pathophysiology has been postulated. The presence of autoantibodies against nervous tissue ${ }^{19}$ or amyloidosis may be an alternative explanation. ${ }^{20}$

Parasympathetic dysfunction, measured by cardiovascular function tests, ${ }^{2122}$ has also been found in other autoimmune diseases such as systemic sclerosis and systemic lupus erythematosus.

The results of our study, showing dysfunction only of the parasympathetic nervous system, are in line with previous studies. In our study the sympathetic nervous system, as reflected by the dilatation latency time, was not impaired, and this concurs with the results of cardiovascular reflex tests in previous studies on rheumatoid arthritis and the other autoimmune diseases. ${ }^{6} 71821-24$

Well known features of parasympathetic failure such as ocular dryness often occur in rheumatoid arthritis. However, the relation between exocrine gland insufficiency and the parasympathetic nervous system in patients with rheumatoid arthritis has not yet been studied. The correlation between parasympathetic dysfunction and ocular dryness in rheumatoid arthritis patients, as found in the present study, suggests a causal relation. Such a correlation was recently also reported in patients with diabetes mellitus. ${ }^{25}$

It is important to point out that a Schirmer test response of $<10 \mathrm{~mm} / 5 \mathrm{~min}$ is observed in about $35 \%$ of the normal population. There is no international agreement about the normal values of this test. However, we chose Schirmer's test because of its simplicity and the lack of other useful tests to measure tear production.

No relation was found between the production of saliva and the results of pupillography. It may be hypothesised that the stimulus of chewing is greater than the autonomic drive for unstimulated saliva production.

Primary Sjögren syndrome is a systemic autoimmune disease characterised by oral and ocular dryness due to salivary and lacrimal gland inflammation. When it occurs in rheumatoid arthritis, this extra-articular manifestation is called secondary Sjögren syndrome. In the patients studied here the presence of exocrine gland inflammation was not investigated. It therefore remains unclear whether the patients with ocular dryness and parasympathetic dysfunction also suffered from secondary Sjögren syndrome. Nevertheless the relation between parasympathetic dysfunction and ocular dryness may be of practical significance. Fox et al showed increased production of saliva in patients with oral dryness following treatment with 
pilocarpine, a parasympathomimetic agent. ${ }^{26}$ Further studies on the treatment of ocular and oral dryness with parasympathomimetic agents in patients with rheumatoid arthritis seems worthwhile.

In conclusion, parasympathetic dysfunction was found in rheumatoid arthritis patients with ocular dryness, suggesting that autonomic nervous system dysfunction plays an aetiological role in this extra-articular feature of rheumatoid arthritis. Further studies on the relative contribution of autonomic dysfunction to ocular dryness in rheumatoid arthritis and possible therapeutic effects of parasympathomimetic agents in rheumatoid arthritis patients with oral and ocular dryness are warranted.

1 Bathon JM, Moreland LW, Dibartolomeo AG. Inflammatory central nervous system involvement in theumatoid
arthritis. Semin Arthritis Rheum 1989;18:258-66.

2 Brick JE, Brick JF. Neurological manifestions of theumatologic disease. Neurol Clin 1989;7:629-39.

3 Chang DJ, Paget A. Neurological complications of rheumatoid arthritis. Rheum Dis Clin North Am 1993;4:955-73.

4 Bennett PH, Scott JT. Autonomic neuropathy in rheumatoid arthritis. Ann Rheum Dis 1965;24:161-8.

5 Kalliomäki J Saarimaa HA, Toivanen P. Axon reflex sweating in rheumatoid arthritis. Ann Rheum Dis 1963; 22:46-9.

6 Leden I, Eriksson A, Lilja B, Sturfelt G, Sundkvist G. Autonomic nerve function in rheumatoid arthritis of varying severity. Scand $\mathcal{F}$ Rheumatol 1983;12:166-70.

7 Toussirot E, Serratrice G, Valentin P. Autonomic nervous system involvement in rheumatoid arthritis. 50 cases. $\mathcal{F}$ Rheumatol 1993;20:1508-14.

8 Moutsopoulos HM. Sjögren's syndrome (sicca syndrome): current Issues. Ann Intern Med 1980;92:212-26.

9 Fox RI, Howell FV, Bone RC. Primary Sjögren Syndrome: Clinical and immunopathologic features. Semin Arthritis Rheum 1984;14:77-105.

10 Bannister R, Mathias CJ. Autonomic failure. A textbook of clinical disorders of the autonomic nervous system, 3rd ed. clinical disorders of the autonomic nervous system, 3 .

11 Low PA. Clinical autonomic disorders. Evaluation and management, 1st ed. Boston: Little, Brown and Co, 1993:263-77.
12 De Vos A, Marcus JT, Peters HFM. The pupillary light reflex in diabetes mellitus: evaluation of a newly developed infrared light reflection method. Diabetes Res 1989; 10:191-5.

13 Arnett FC, Edworthy SM, Bloch DA. The American Rheumatism Association 1987 revised criteria for the classification of theumatoid arthritis. Arthritis Rheum 1988;31:315-24.

14 Van Bijsterveld OP. Diagnosis and differential diagnosis of keratoconjunctivitis sicca associated with tear gland degeneration. Clin Exp Rheumatol 1990;8(suppl 5):3-6.

15 van der Heijde DMFM, van't Hof MA, van Riel PLCM. Judging disease activity in clinical practice in rheumatoid arthritis: first step in the development of a disease activity score. Ann Rheum Dis 1990;49:916-20.

16 Kohler PF, Winter ME. A quantitative test for xerostomia. The Saxon test, an oral equivalent of the Schirmer test. Arthritis Rheum 1985;28:1128-32.

17 Perry F, Heller PH, Kamiya J, Levine JD. Altered autonomic function in patients with chronic myofacial pain. Pain 1989;39:77-84.

18 Edmonds ME, Jones TC, Saunders WA. Autonomic neuropathy in rheumatoid arthritis. BMF 1979;ii:173-5.

19 Appenzeller O, Arnason BG, Adams RD. Experimental autonomic neuropathy: an immunological induced disorder of reflex vasomotor function. $\mathcal{F}$ Neurol Neurosurg Psychiatry 1965;28:510-5.

20 Nordborg C, Kristensson K, Olsson Y, Sourander P. Involvement of the autonomic nervous system in primary and secondary amyloidosis. Acta Neurol Scand 1973; 49:31-8.

21 Dessein PH, Joffe BI, Metz RM. Autonomic dysfunction in systemic sclerosis: sympathetic overactivity and instability. Am ₹ Med 1992;93:143-50.

22 Hermosillo AG, Ortiz R, Dabague J. Autonomic dysfunction in diffuse scleroderma vs crest: an assessment by computerized heart rate variability. $f$ Rheumatol 1994; 21:1849-54.

23 Omdal R, Jorde R, Mellgren SI, Husby G. Autonomic function in systemic lupus erythematosus. Lupus 1994;3: 413-7.

24 Klimiuk PS, Taylor L, Baker RD, Jayson MIV. Autonomic neuropathy in systemic sclerosis. Ann Rheum Dis 1988; 47:542-5.

25 Ramos-Remus C, Suarez-Almazor M, Rusell AS. Low tear production in patients with diabetes mellitus is not due to Sjögren's syndrome. Clin Exp Rheumatol 1994;12:375-80.

26 Fox PC, Atkinson JC, Macynski RN. Pilocarpine treatment of salivary gland hypofunction and dry mouth (xerostomia). Arch Intern Med 1991;151:1149-52. 